\title{
EXPERIMENTAL INVESTIGATION OF COLD START EMISSIONS USING ELECTRICALLY HEATED CATALYSTS IN A SPARK IGNITION ENGINE
}

\author{
K. Bhaskar ${ }^{1}$, G. Nagarajan $^{2}$ and S. Sampath ${ }^{3}$ \\ ${ }^{1}$ Department of Automobile Engineering, Sri Venkateswara College of Engineering, \\ Sriperumbudur 602 105, India. Phone : 91-44-27152000, \\ Email: bhaskar66@svce.ac.in \\ ${ }^{2}$ Department of Mechanical Engineering, Anna University, Chennai-600 025, India \\ ${ }^{3}$ Department of Automobile Engineering Rajalakshmi Engineering College, \\ Sriperumbudur 602 105, India
}

\begin{abstract}
The population of spark-ignition vehicles in urban areas is very high and is increasing rapidly due to their convenience for short distance transportation. These vehicles are major sources of urban air pollution compared to vehicles with diesel engines. Catalytic converters are used to control their emissions but they attain their maximum conversion rates of about $80 \%-90 \%$ under optimum operating conditions and are not effective during cold start conditions. The objective of the present work is to demonstrate that an electrically heated catalyst (EHC) in combination with a traditional converter can achieve the Low and Ultra Low Emission Vehicle (LEV, ULEV) standards. Experiments were conducted to investigate the impact of various metal oxides in EHC and design parameters to reduce cold-start emissions of a multi-cylinder SI engine. It is observed that EHC reduces cold-start hydrocarbon and carbon monoxide emissions when used with an existing catalytic converter. The maximum $\mathrm{CO}$ and $\mathrm{HC}$ reductions were achieved with copper oxide as the catalyst in EHC with air injection of $80 \mathrm{lpm}$ for $40 \mathrm{sec}$ after cold start of the engine.
\end{abstract}

Keywords: Cold Start Emission, Electrically Heated Catalyst, Metal Oxide Catalyst, HC emission, $\mathrm{CO}$ emission

\section{INTRODUCTION}

Since the first federal legislation regarding emission limits in the United States in 1975, the market for emission control devices has been expanding rapidly and attracting interest for environmental, economical and scientific reasons. The moving force behind it is the social pressure for environmentally friendly engineering and pollution reduction and it is reflected in the gradually more stringent automotive emission legislation in most countries. The automotive industry responded to the legislation by introducing exhaust gas after-treatment systems whose heart is the catalytic converter. The catalytic converter is a remarkable chemical reactor, in the sense that: it is designed under space, pressure-drop and cost-of-production constraints, it is required to operate with maximum conversion efficiency under fully transient conditions of temperature, input gas flow rate and input gas composition, and it is subject to a chemically hostile environment. The above requirements for the converter's operation posed significant and fascinating challenges for the engineer and the scientist. 
Catalytic converters attain maximum conversion rates of about $80 \%-90 \%$ under optimum operating conditions but they are not effective during cold start conditions. A cold start is defined as an engine start following a 12 to 36 hours continuous vehicle soak in a constant temperature environment of $20^{\circ} \mathrm{C}$ to $30^{\circ} \mathrm{C}$. Two factors contributing to the high emission at cold start are that the catalyst does not begin to oxidize $\mathrm{HC}$ and $\mathrm{CO}$ until it reaches light off temperature and engines run with a rich mixture during warm-up. The light off temperature is generally defined as the temperature at which catalyst becomes more than 50\% effective. Approximately $60 \%$ of the overall $\mathrm{HC}$ and $\mathrm{CO}$ emissions are emitted during the first 180 seconds from the cold-start period. To control cold start emission, some of the techniques reported are: electrically heated catalyst (EHC), hydrocarbon storage devices, exhaust gas ignition, close coupled catalyst, fuel burner, pre-catalyst, use of fast response $\mathrm{O}_{2}$ (UEGO) sensor and vacuum insulated catalytic converter. The present investigation is focussed on the study of cold start emission control using an electrically heated catalyst (EHC).

Day and Socha (1988) have investigated the impact of physical (cell density, frontal area, volume) and material (porosity, mass) design parameters on vehicle emission and pressure drop. It is reported that larger volume and/or higher cell density substrates reduce cold start $\mathrm{CO}$ and $\mathrm{HC}$ emissions and material changes have little or no impact on catalyst performance. It is concluded that pressure drop could be increased by using a longer substrate and dramatically reduced with a larger frontal area. Socha and Thompson (1992) have reported that an extruded metal electrically heated catalyst (EHC) in combination with a traditional main converter can achieve the low emission standards. It is reported that non-methane hydrocarbon (NMHC) emissions range from 0.15 to 0.3 . $\mathrm{g} / \mathrm{mile}$ for such systems and that emissions and energy usage are minimized when the EHC is placed adjacent to the main converter and when the EHC system is located close to the engine. They have further concluded that the main converter does the majority of the conversion during cold start rather than EHC. Horng et al. (2003) reported that fast startup reactor with an electrically heated metallic catalyst can be accomplished by preheating the reactant gas or by mixing an excess amount of oxygen (air) for complete conversion. Horng and $\mathrm{Wu}$ (2005) investigated the effect of heat storing material in combination with EHC on input energy while reducing the cold start emissions. They reported that shorter heat storing material resulted in a more rapid rise in catalyst temperature and a lower input energy than a longer one.

Significant improvements were made in the last two decades to reduce power consumption to 2 to $3 \mathrm{~kW}$ level from the initial $5 \mathrm{~kW}$ level while providing faster heat up characteristics to eliminate the need for pre-heating and reducing the severe battery impact. However, even a $2 \mathrm{~kW}$ power requirement has a substantial impact on battery life and requires large wire diameters and a sophisticated power switching mechanism (Yaegashi et al., 1994). A more practical solution may be necessary to best utilize sources of energy available to heat the catalyst such as electrical energy, sensible energy and the chemical energy of the exhaust. The rate of temperature rise is proportional to the mass of the converter. By optimizing the heated mass, the rate of temperature rise can be increased to a great extent. Once the exothermic reaction begins, chemical energy is released which acts to heat up the main converter which helps to reduce the time required for activating the catalyst. The aim of this work is to reduce cold start emissions by using metal oxide catalysts with EHC placed adjacent to the main converter. The position of the EHC is also optimized to reduce the power consumption. 


\section{EXPERIMENTAL APPARATUS AND PROCEDURE}

\section{Catalysts used for investigation}

Generally catalysts made from precious metals such as platinum, palladium and rhodium are best suited for catalytic converters but they are very costly. These precious metals are impregnated in a highly porous surface of the ceramic honeycomb structure. Heating of ceramic honeycomb structures is difficult due to their low thermal conductivity. Transient metal oxides are chosen for EHC as catalysts as they are easily available and they are good conductors of heat. Some of the transition metal oxides are the oxides of copper, nickel, chromium and silver. The base metal substrate is prepared for electroplating by degreasing, de-rusting and the removal of surface scales. Then 2.2 $\mathrm{g} / \mathrm{cft}$ of metal catalyst were loaded on the substrate by electroplating and oxidized. In this paper the effect of copper oxide and silver oxide catalysts is discussed in detail.

EHC consists of a heater element and metal oxide catalyst. The EHC is placed just before the main converter in the exhaust manifold as shown in Figure 1. The EHC is electrically connected to the main electrical system of the vehicle through a power switch. The EHC quickly reaches high temperature levels sufficient for $\mathrm{CO}$ and $\mathrm{HC}$ conversion by electrical heating before starting the engine. Secondary air is supplied during the cold start period to provide enough oxygen to initiate and sustain the chemical reaction. The exhaust gas carries the heat generated by the exothermic oxidation in EHC down to the main converter, which consequently attains faster light off. The EHC volume is approximately $20 \%$ that of the commercially available main converter (MC). The advantage of this configuration is that the main converter lights off quickly.

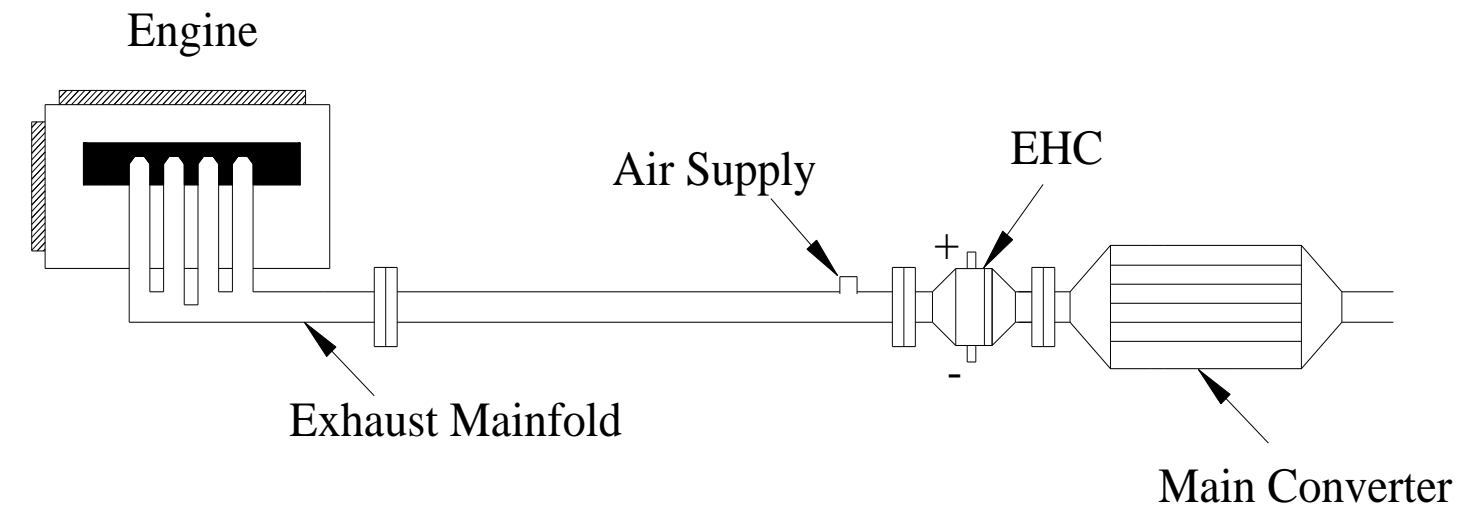

Figure 1: EHC-MC Configuration 


\section{Experimental Setup}

The schematic diagram of the complete experimental set-up is shown in Figure 2 and the specifications are given in Table 1. Experiments were conducted on a multicylinder, vertical, water-cooled, four stroke, spark ignition engine, coupled to a hydraulic dynamometer. The engine was mounted on the bed with suitable connections for the fuel and cooling water supply. Tests were conducted at $1500 \pm 50 \mathrm{rpm}$. The EHC was placed before the main catalytic converter in the exhaust pipe. The EHC housing was made of stainless steel and insulated to prevent heat loss from the piping to the surroundings. The substrate was made of stainless steel mesh. The concentric surface of the mesh was filled with metal oxide catalyst $\left(145 \mathrm{~cm}^{3}\right.$ volume $)$ and the mesh was heated with a $1 \mathrm{~kW}$ band type electrical heater.

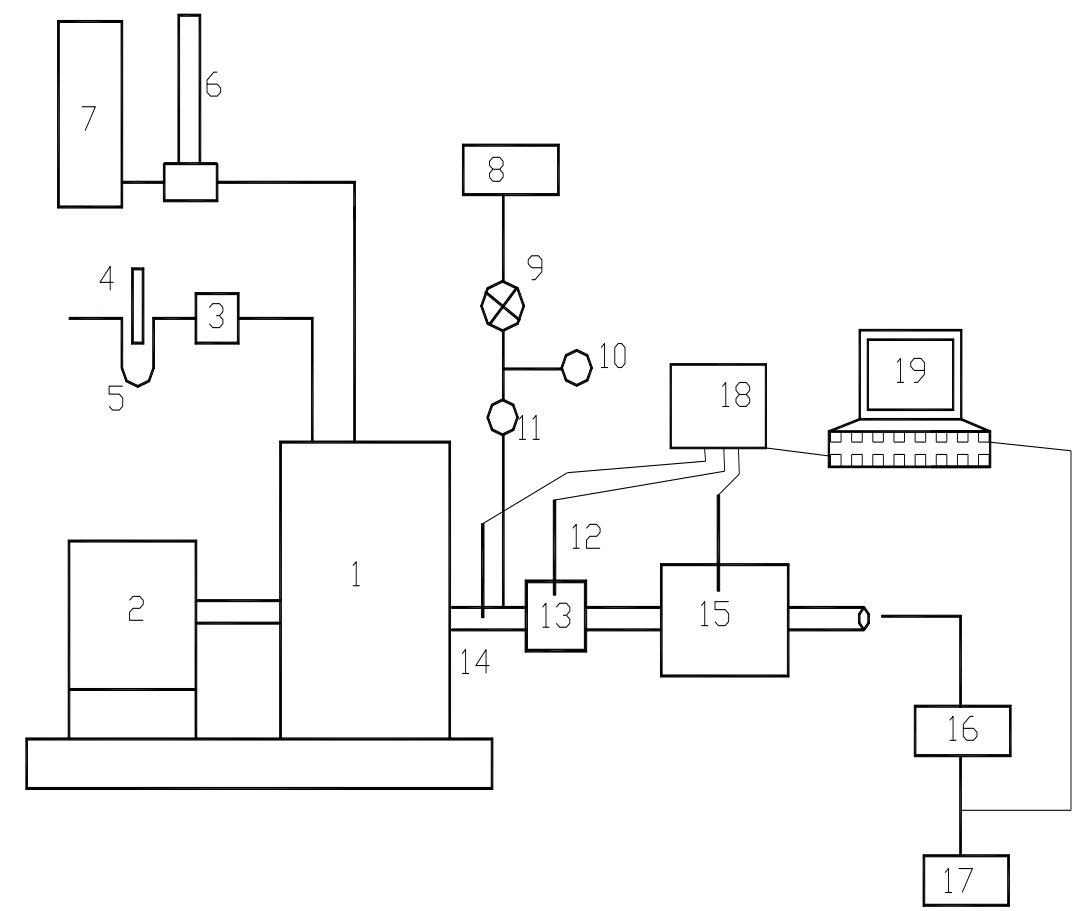

1. Engine

2. Loading device

3. Air tank

4. Orifice

5. Manometer

6. Burette

7. Fuel tank

8. Air compressor

9. Flow regulator
10. Pressure gauge

11. Flow meter

12. Thermocouple

13. Exhaust pipe

14. EHC

15. Main cc

16. Analyser

17. Printer

18. Data logger

Figure 2: Experimental set-up

The inner cylinder was also filled with metal oxide catalyst, which acts as a light-off catalyst. The main converter used was a three way converter supplied by the OEM that had been exposed to approximately 5000 kilometers of vehicle operation. The 
inlet, bed, and outlet temperatures of the EHC and the bed temperatures of the main converter were measured by four cromel-alumel thermocouples. All these thermocouples were connected with a PC based 8-channel 12-bit data logging system to register the temperature variation. The gas analyser (Crypton 285 OIML II- SPEC) was used for the measurement of $\mathrm{HC}$ and $\mathrm{CO}$ in the exhaust. The response time of the gas analyser is 10 seconds. Air was supplied from a compressor on the leading side of the EHC in the exhaust pipe at $80 \mathrm{lpm}$ for the first 40 seconds and the supply is then stopped. Regulator and rotometer were used to regulate and measure the air supply.

Table 1: Specifications of the engine

\begin{tabular}{ll}
\hline \multicolumn{1}{c}{ Parameter } & \multicolumn{1}{c}{ Description } \\
\hline Make & Ambassador \\
Model & Mark IV - Water-cooled, four \\
& cylinder, four stroke SI engine. \\
Bore & $73.02 \mathrm{~mm}$ \\
Stroke & $88.9 \mathrm{~mm}$. \\
Displacement & $1489 \mathrm{CC}$. \\
No. of Cylinders & 4 \\
Gross BHP & 46.5 at 4200 rpm \\
Firing Order & $1-3-4-2$ \\
Compression ratio & $7.2: 1$ \\
\hline
\end{tabular}

\section{Experimental Procedure}

The engine is soaked for 12 hours the previous night so that it is in cold start condition at the beginning of the experiment. The electrical heating system is started so that the catalyst surface temperature is about $300^{\circ} \mathrm{C}$. The engine is now started and the speed adjusted to the value of $1500 \pm 50 \mathrm{rpm}$. The experiment is conducted for 180 seconds from cold start. Cold start $\mathrm{HC}$ and $\mathrm{CO}$ emissions were measured using the exhaust gas analyser. The inlet, bed, and outlet temperatures of the EHC and the bed temperatures of the main converter were measured by four cromel-alumel thermocouples.

During the cold-start phase, the engine must be run with richer than stoichiometric fuel mixtures in order to ensure smooth operation. The chemical reactions that occur in the EHC are the oxidation of hydrocarbon and the oxidation of carbon monoxide. As the air-fuel mixture is rich, lack of oxygen during this period in the catalytic converter allows for only partial oxidation of $\mathrm{CO}$ and $\mathrm{HC}$, thus resulting in higher exhaust gas emissions. This necessitates the injection of secondary air which was supplied from a compressor at constant pressure through a nozzle provided on the leading side of the EHC in the exhaust pipe. The injected air reacts with the hot exhaust gas, thus allowing for an initial oxidation of $\mathrm{CO}$ and $\mathrm{HC}$ to take place in the exhaust pipe. The heat produced by the oxidation reactions increases the exhaust gas temperature, resulting in a fast catalyst light off. 


\section{RESULTS AND DISCUSSION}

The results of experiments conducted with electrically heated metal catalytic converter and main catalytic converter in the four-stroke SI engine with $1 \mathrm{~kW}$ electrical heating are presented in the following section:

\section{Effect of Copper Oxide as Catalyst in EHC}

Figure 3 shows the variations of temperatures with time for: the exhaust gas without after-treatment devices (ATD), the surface of the main converter (MC) alone (without EHC), the surface of the EHC for the EHC-MC configuration without air supply, and the surface of the MC for the EHC-MC configuration without air supply. The variation of temperature of the exhaust gas without ATD and the surface temperature of the MC without $\mathrm{EHC}$ are shown for the purpose of comparison. It is seen that the temperature of the EHC reaches $312^{\circ} \mathrm{C}$ due to electrical heating before starting the engine. The temperature in the EHC decreases gradually and reaches a minimum of $280^{\circ} \mathrm{C}$ after 36 seconds from cold start, due to the relatively cool exhaust gas entering the EHC. It is further seen that the temperature of the EHC increases till 132 seconds due to the exothermic energy created in the EHC and after that it remains almost steady. It is noted that the surface temperature of the MC without EHC shows a steady increase in time after a cold start and the same trend is observed for the MC in the EHC-MC configuration with a marginal rise in temperature at all times after cold start. This increase may be due to the energy transfer during the exothermic reaction in the EHC. It can be seen from the figure that the MC reaches a light off temperature of $250{ }^{\circ} \mathrm{C}$ after 132 seconds from cold start.

The variations of temperature with time for the above configurations with air supply are shown in Figure 4. It is seen that the temperature of the EHC reaches $312^{\circ} \mathrm{C}$ due to electrical heating before starting the engine as in the previous case. The temperature of the EHC decreases gradually and reaches $246^{\circ} \mathrm{C}$ after 48 seconds from cold start, due to the relatively low temperature exhaust gas and cool secondary air entering the EHC. It is further seen that the temperature of the EHC increases up to 145 seconds due to the exothermic energy created in the EHC. The surface temperature of the MC without EHC shows a steady increase with respect to time after the cold start and the same trend is observed for the MC in the EHC-MC configuration at all times after cold start. It is seen from the figure that the $\mathrm{MC}$ in this configuration reaches a light off temperature around $250^{\circ} \mathrm{C}$ after 120 seconds from cold start due to a higher energy transfer in the presence of secondary air. 


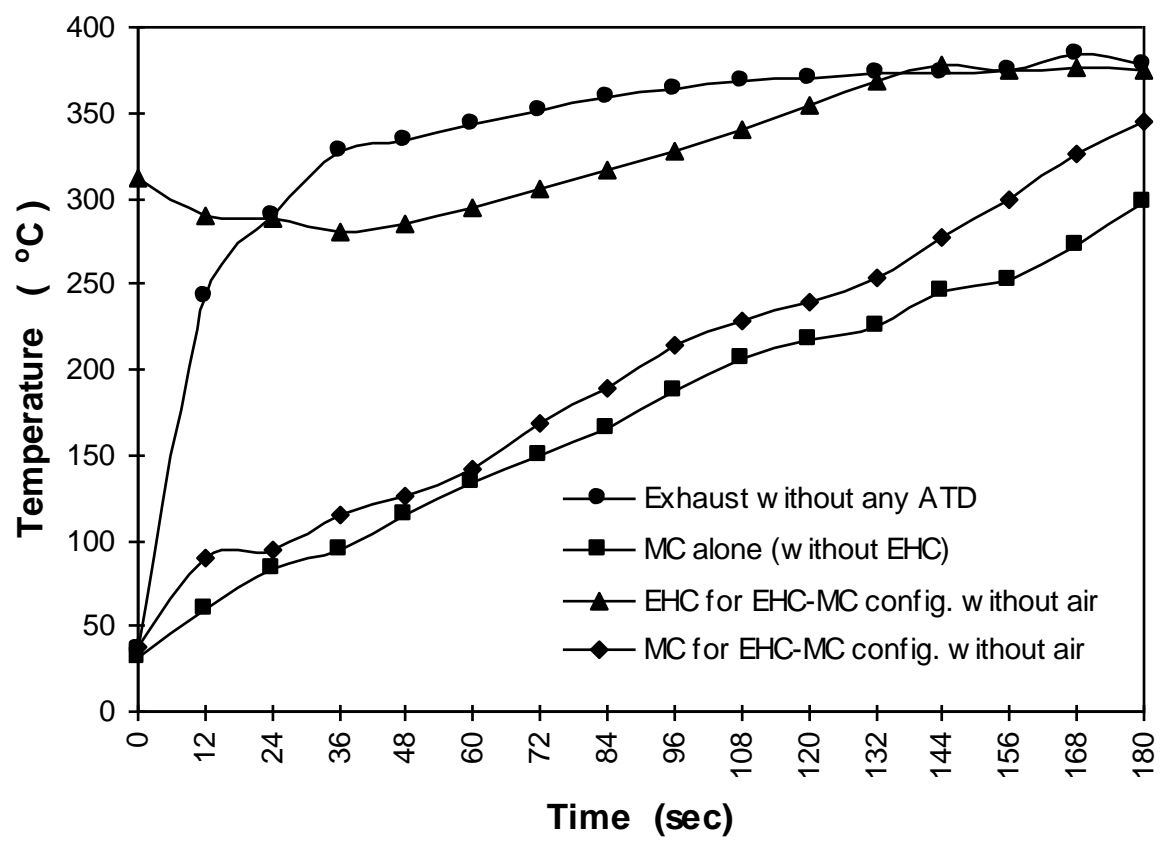

Figure 3. Temperature vs time for copper oxide as catalyst in EHC without air supply

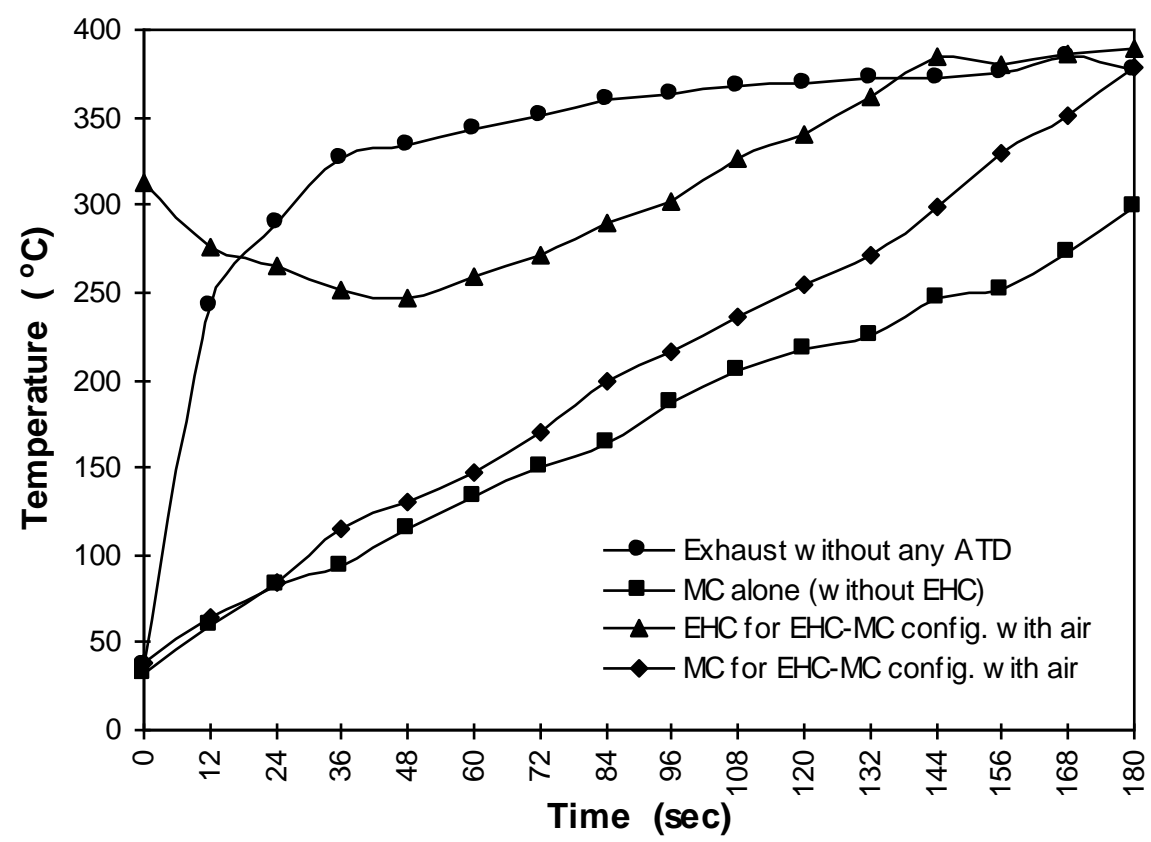

Figure 4. Temperature vs time for copper oxide as catalyst in EHC with air supply

Figure 5 shows the variations of surface temperatures of the $\mathrm{MC}$ alone (without EHC), MC for EHC-MC configuration without air supply and MC for EHC-MC configuration with air supply. It is noted that the surface temperature of the MC in all cases shows a steady increase with respect to time after a cold start. The surface temperature of the MC for the EHC-MC configuration with air supply is higher than that without air supply due to the higher exothermic heat release because of the availability of more oxygen in secondary air. 
The variations of $\mathrm{CO}$ in the exhaust with time from cold start of the engine for the above configuration are shown in Figure 6. It is seen that $\mathrm{CO}$ percentage by volume is higher in the engine exhaust without any ATD and gradually decreases with time and a similar trend is seen in all other cases. CO emissions are lower in all other cases and it is lowest with air supply due to the availability of more oxygen in the secondary air supplied. It is observed that the EHC-MC configuration gives a maximum reduction of about $50 \%$ after 144 seconds from the cold start while the maximum reduction of $65 \%$ is obtained after 132 seconds for the EHC-MC configuration with air supply.

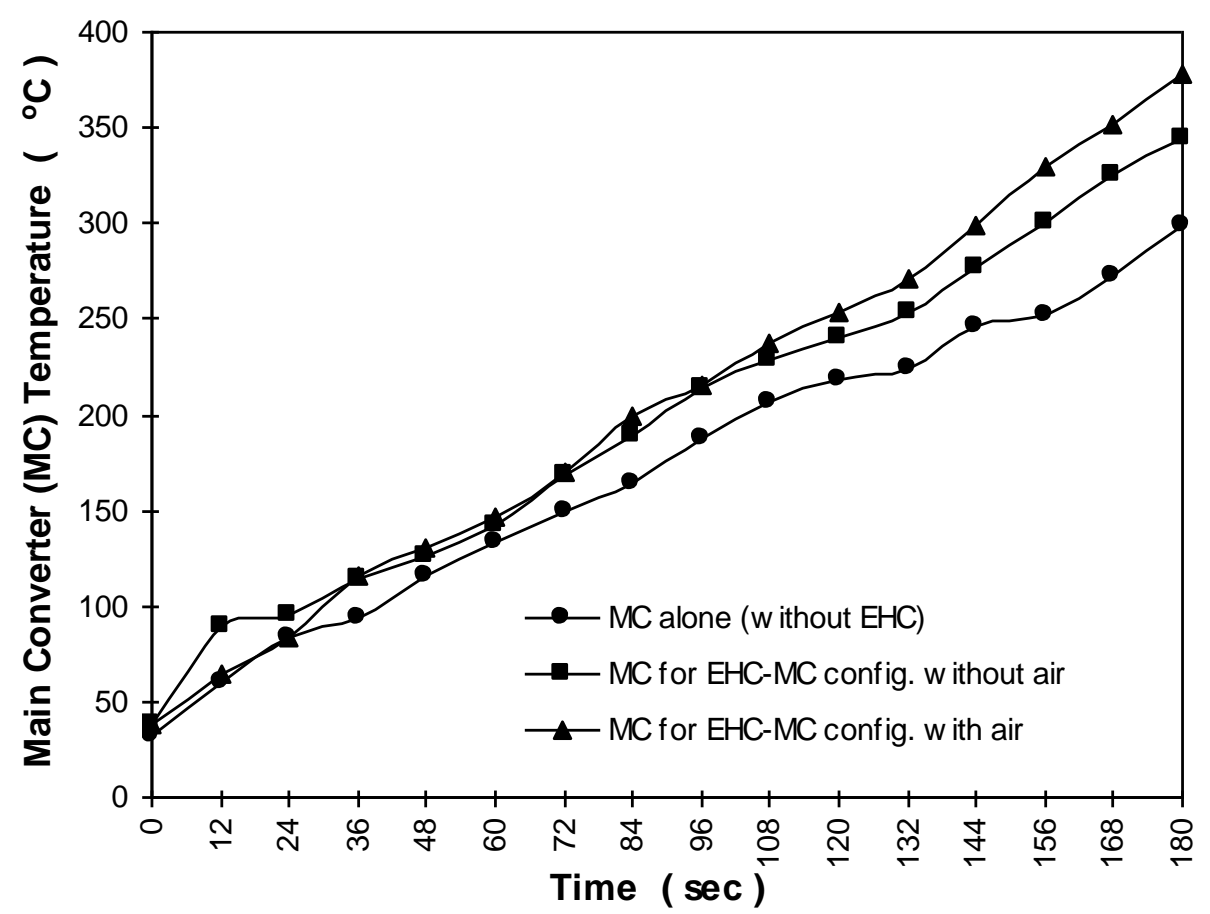

Figure 5. Main converter (MC) temperature vs time for copper oxide as catalyst in EHC

Figure 7 shows the variation of $\mathrm{HC}$ with time from cold start of the engine for the various configurations. It is seen that $\mathrm{HC}$ emissions are higher in the engine exhaust at the beginning and gradually decrease with time. A similar trend is observed in all other cases. The HC content is higher in the engine exhaust without any ATD, and it is the lowest for the EHC-MC configuration with air supply. For the other two configurations it lies in between the above two cases. The EHC-MC configuration without air supply gives the maximum reduction of about $28 \%$ after 60 seconds while with air supply it gives a reduction of $38 \%$ after 60 seconds due to the availability of more oxygen in the secondary air supply. In this work, the electrical power requirement is restricted to I kW when compared to $1.5 \mathrm{~kW}$ by F. Terres et al. (1996), who used platinum based oxides, but copper oxide catalyst is very much cheaper. The emissions of $\mathrm{CO}$ and $\mathrm{HC}$ with copper oxide metal catalyst are found to be comparable with those measured by Sendilvelan et al. (2001). 


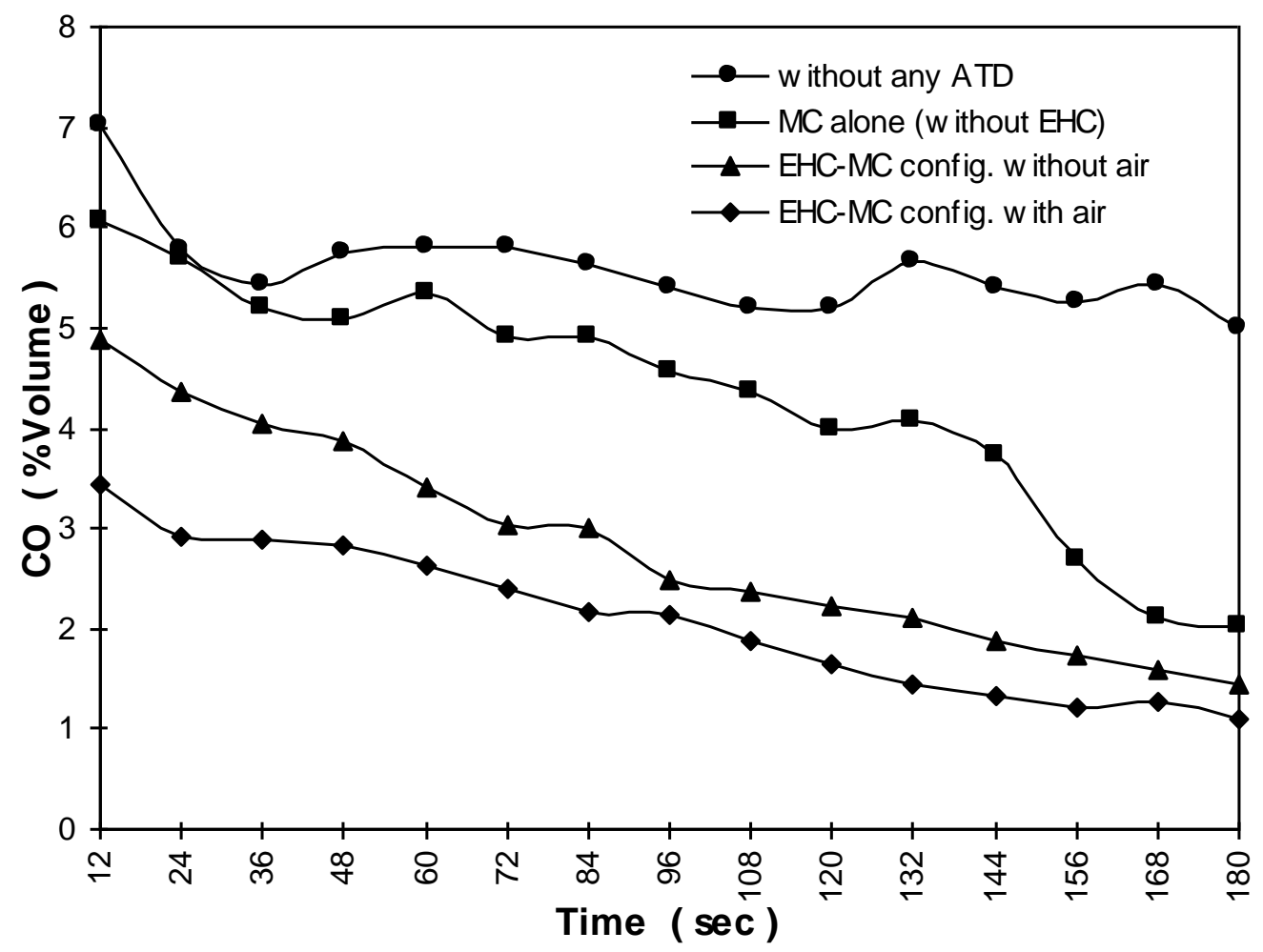

Figure 6. Carbon monoxide vs time for copper oxide as catalyst in EHC

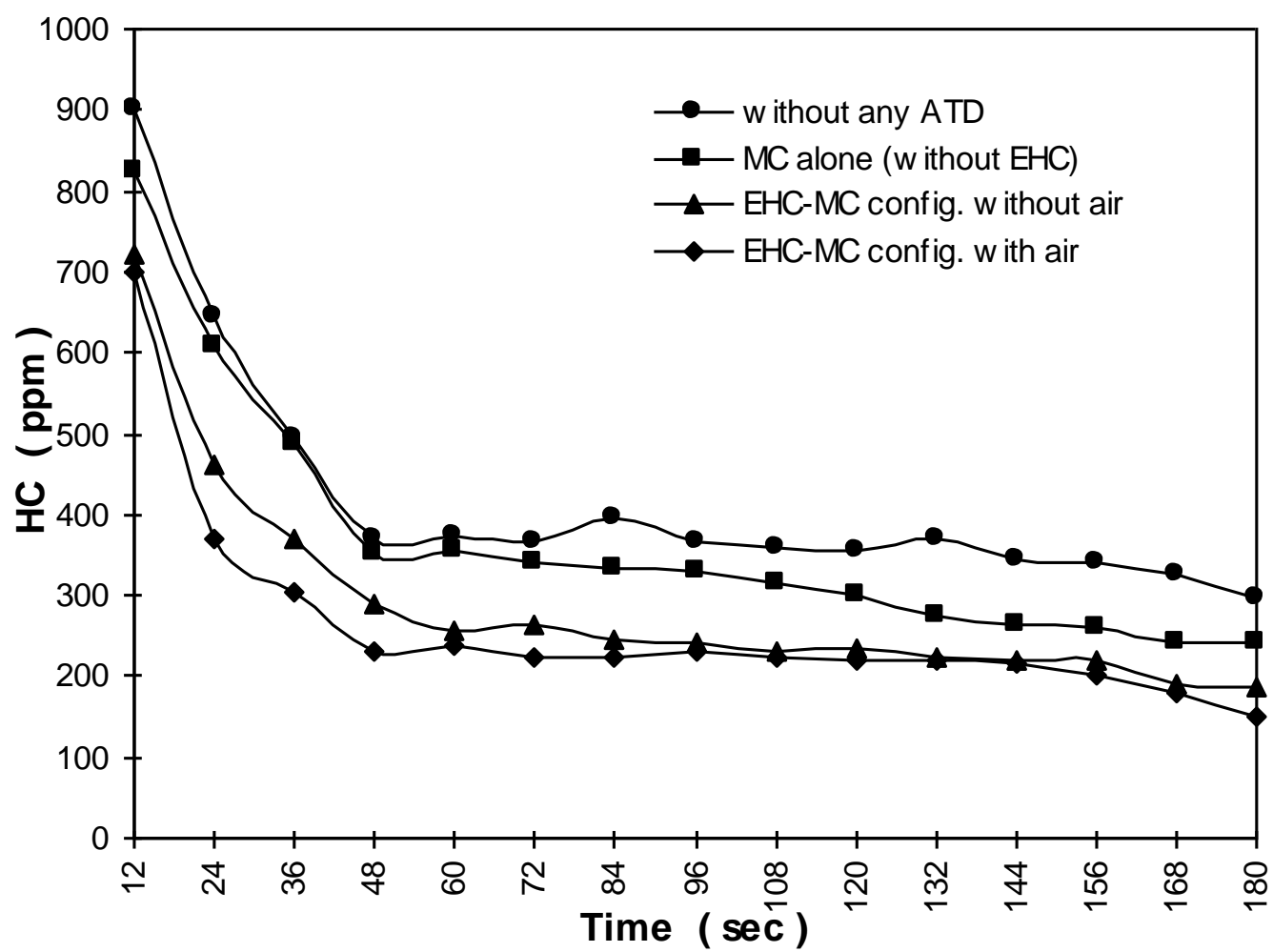

Figure 7. Hydrocarbon vs time for copper oxide as catalyst in EHC 


\section{Effect of Silver Oxide as Catalyst in EHC}

Figure 8 shows variations of exhaust gas temperatures for the various cases with silver oxide as catalyst in EHC. It is seen that the EHC temperature reaches $312^{\circ} \mathrm{C}$ due to electrical heating before starting the engine. The EHC temperature decreases gradually and reaches $263^{\circ} \mathrm{C}$ after 48 seconds from cold start due to the relatively low temperature exhaust gas entering the EHC. The temperature of the EHC increases until 144 seconds due to the exothermic energy created in the EHC and after that it remains almost steady. The surface temperature of the MC without EHC shows a steady increase with time after cold start and the same trend is observed for the MC in EHC-MC configuration with a lower temperature rise at all times after cold start. This may be due to the lower exothermic heat release in EHC with silver oxide catalyst. It is observed that the MC reaches a light off temperature after 156 seconds from cold start.

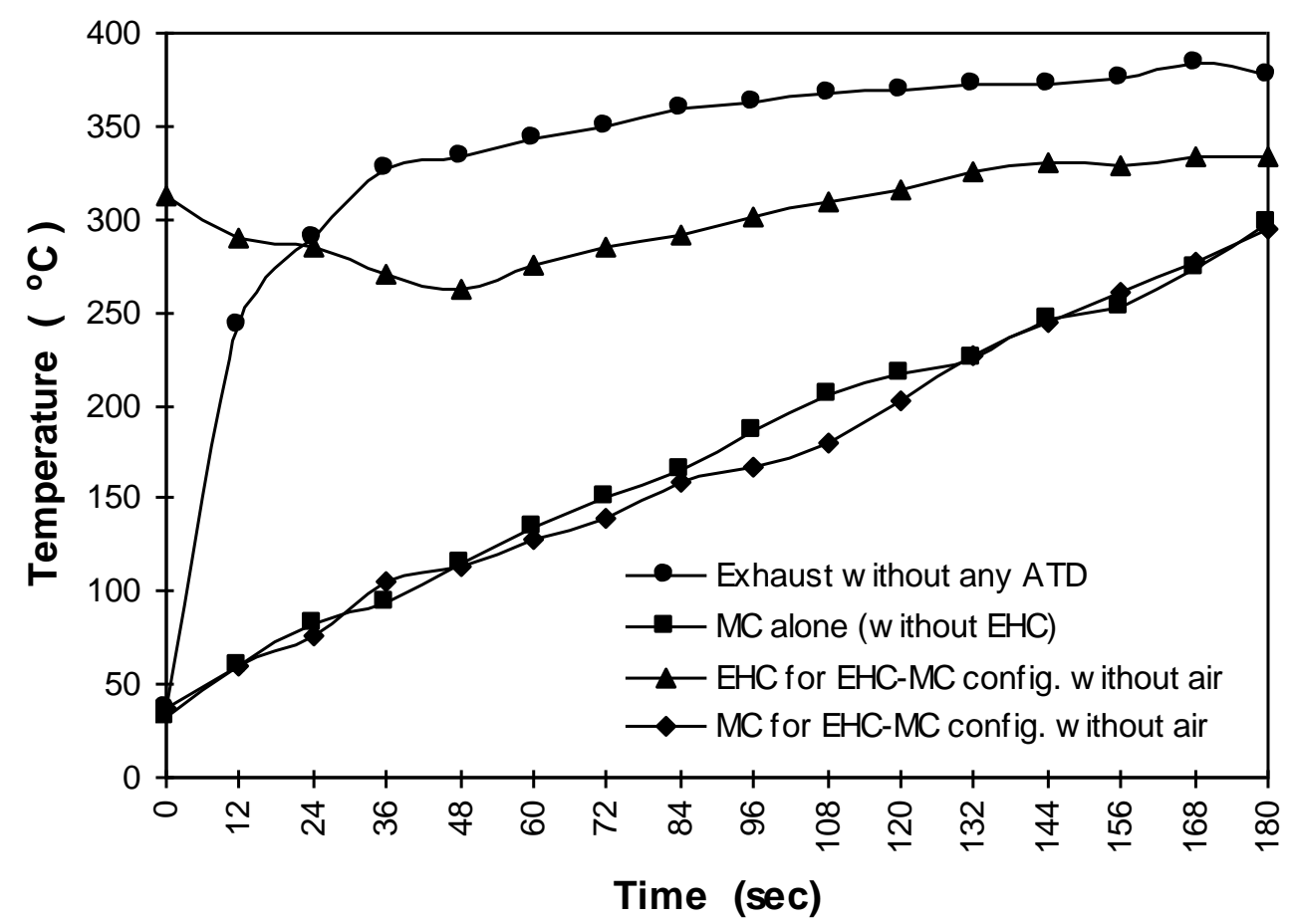

Figure 8. Temperature vs time for silver oxide in EHC without air supply

The variations of exhaust gas temperature for the various cases are shown in Figure 9. It is seen that the EHC temperature reaches $312^{\circ} \mathrm{C}$ due to electrical heating before starting the engine as in the previous case. The EHC temperature decreases gradually and reaches $241^{\circ} \mathrm{C}$ after 48 seconds from cold start due to the relatively low temperature exhaust gas and cool secondary air entering the EHC. The temperature of the EHC increases upto 120 seconds due to the exothermic energy created in EHC. The surface temperature of $\mathrm{MC}$ without EHC shows a steady increase with time after cold start and the same trend is observed for the MC in EHC-MC configuration at all times after cold start. This increase may be due to the energy transfer during the exothermic reaction in EHC and the noteable heat of the exhaust gas. It is observed that the main converter reaches light off temperature around $250^{\circ} \mathrm{C}$ after 144 seconds from cold start. 


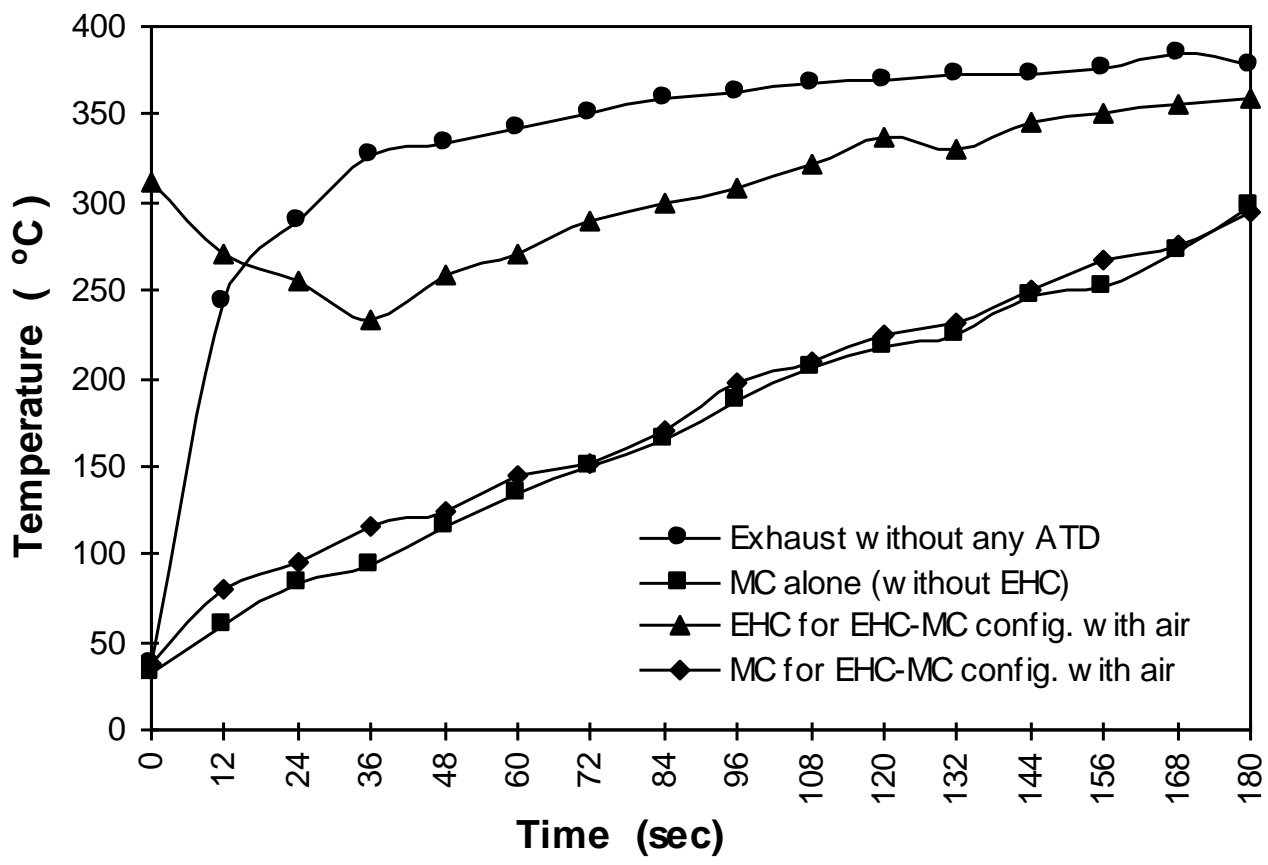

Figure 9. Temperature vs time for silver oxide as catalyst in EHC with air supply

Figure 10 shows variations of exhaust gas temperature with time for the various cases. Note that the surface temperature of MC in all cases shows a steady increase with time after cold start. The surface temperatures of the MC for EHC-MC configuration with air supply and without air supply are almost the same due to the lower exothermic heat release with silver oxide catalyst in EHC.

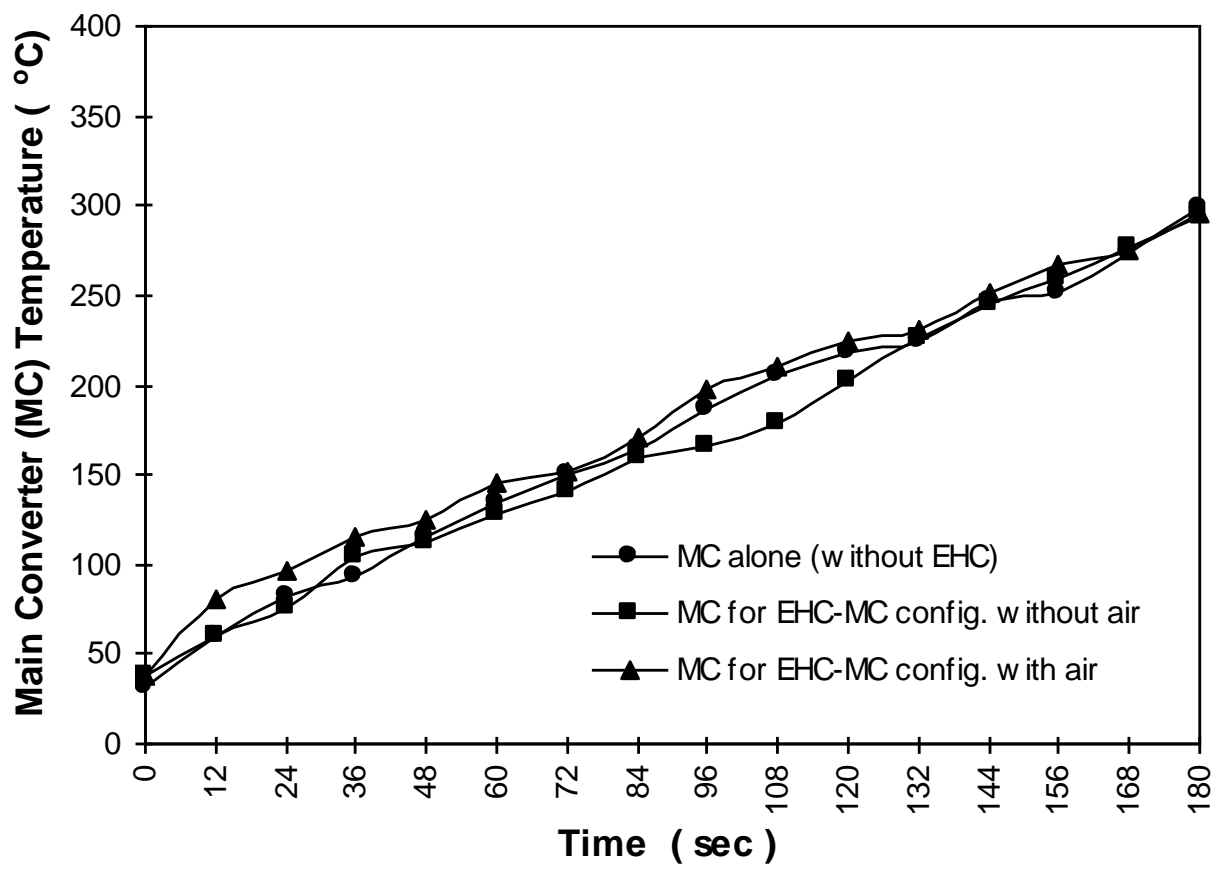

Figure 10. Main converter (MC) temperature vs time for silver oxide as catalyst in EHC 
Figure 11 shows the variations of $\mathrm{CO}$ emissions in the exhaust with time from cold start of the engine for the various cases. It is seen that $\mathrm{CO}$ percentage by volume is higher in the engine exhaust without any ATD and gradually decreases with time and a similar trend is seen in all other cases. The $\mathrm{CO}$ percentage by volume is lower for the EHC-MC configuration without air supply and still lower for the EHC-MC configuration with air supply due to the availability of more oxygen. A maximum reduction of $12.5 \%$ is obtained after 96 seconds from cold start for the EHC-MC configuration without air supply and a $27.5 \%$ reduction is achieved for the EHC-MC configuration with air supply after 132 seconds, compared to MC alone.

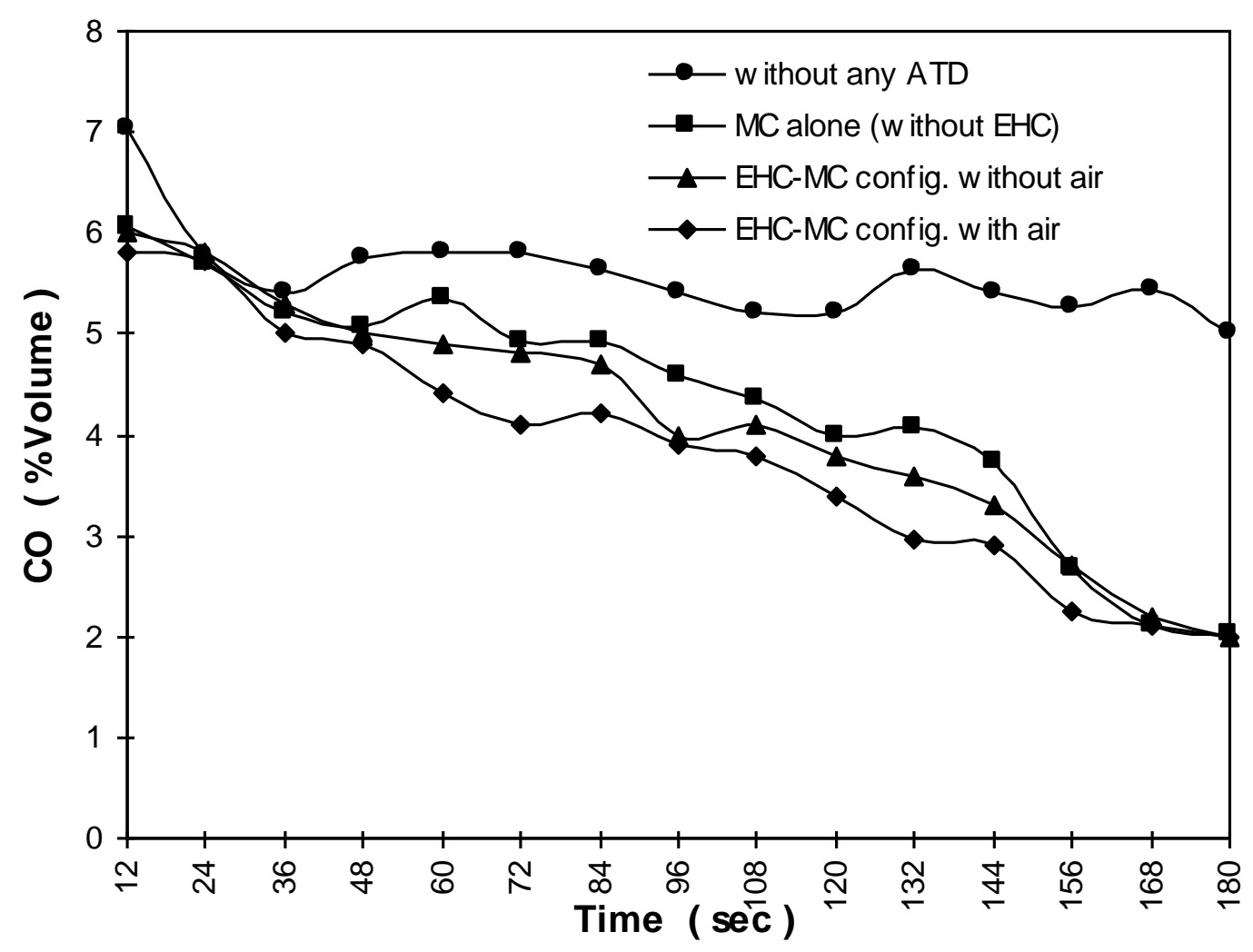

Figure 11. Carbon monoxide vs time for silver oxide as catalyst in EHC

Figure 12 shows the variations of $\mathrm{HC}$ emissions in the exhaust with time from cold start of the engine for the various cases. It is seen that $\mathrm{HC}$ emissions are higher in the engine exhaust without any ATD and gradually decrease with time and a similar trend is seen in all other cases, with lower values. It is to be noted that there is no variation observed in all the other cases, as the temperature of the MC remains same. 


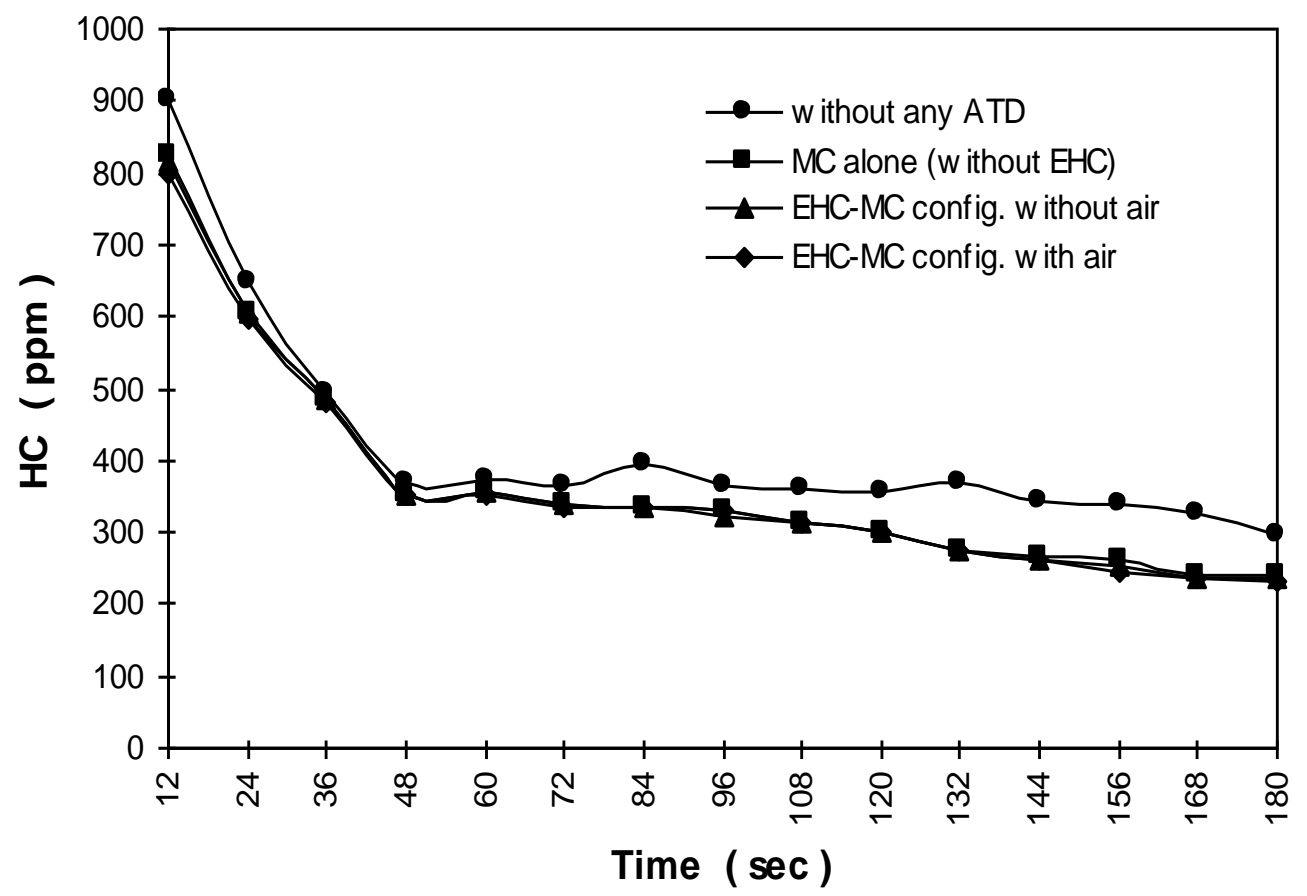

Figure 12. Hydrocarbon emission vs time for silver oxide as catalyst in EHC

\section{CONCLUSIONS}

Based on the experimental investigations carried out, the following conclusions can be drawn:

i. Light off temperature is found to occur earlier with an EHC-MC configuration compared to a MC configuration for metal oxide catalyst and supply of air quickens further.

ii. Copper oxide catalyst is found to be more effective in the reduction of both $\mathrm{CO}$ and HC emissions while using EHC, compared to a silver oxide catalyst. A maximum reduction in $\mathrm{CO}$ emission of $65 \%$ was achieved after 132 seconds in the case of copper oxide compared to $27.5 \%$ in the case of silver oxide. A maximum reduction of $28 \%$ in $\mathrm{HC}$ emission was observed with copper oxide catalyst while no appreciable change was observed with silver oxide catalyst

iii. With air supply, reductions in the emissions of both $\mathrm{CO}$ and $\mathrm{HC}$ are found to be higher. EHC-MC configuration with copper oxide gives a maximum reduction of 50\% CO emission 144 seconds after cold start without air supply and a maximum reduction of $65 \% \mathrm{CO}$ emission 132 seconds after cold start with air supply.

iv. The EHC-MC configuration with copper oxide gives a maximum reduction of $28 \%$ HC emission 80 seconds after cold start without air supply and a maximum reduction of $38 \% \mathrm{CO}$ emission 60 seconds after cold start with air supply.

\section{ACKNOWLEDGEMENTS}

The authors are grateful to the management of the Sri Venkateswara College of Engineering for providing support and encouragement.. 


\section{REFERENCES}

Day, J.P., and Socha, L.S. (1988) Impact of Catalyst Support Design Parameters On Automotive Emissions. SAE Transactions, Paper No. 881590, pp. 3592-3602.

Hanel, F.J., Otto,E. and Bruck, R. (1996) Electrically Heated Catalytic Converter (EHC) in the BMW ALPINA B12 5.7 Switch-Tronic. SAE Transactions, Paper No. 960349 , pp. 228-234.

Heimrich, M. J. (1990) Air Injection to an Electrically Heated Catalyst for Reducing Cold Start Benzene Emissions From Gasoline Vehicles. SAE Transactions, Paper No. 902115, pp. 714-725.

Horng, R.F. (2005) Effect of Input Energy on the Cold Start Characteristics of an Ehc With Heat Storing Material on a Motorcycle Engine. International Journal of Energy Conversion and Management, 46: 1043-1057.

Horng, R.F. and Wu, T.S. 2005. Energy Requirement Assessment on an Electrically Heated Catalyst With Heat Storing Material of a Small Four Stroke Engine During Cold Start. International Journal of Automobile Engineering, 219(12): 1469-1479.

Horng, R.F., Chou, H.M., Chou, T. and Hsu, T.C. 2003. Reaction of the Electrically Heated Catalyst of a Four Stroke Motorcycle Engine Under Cold Start Conditions With Additional Enrichment of the Intake Mixture. International journal of Automobile Engineering, 217(12): 1117-1124.

Sendilvelan, S. , Jeyachandran, K. and Bhaskar, K. 2001. Pollution Studies on Gasoline Engine With Electrically Heated Catalyst. Presented in IC engine division of ASME, USA, pp. 95-99.

Socha, L.S. and Thompson, J.D.F. 1992. Electrically Heated Extruded Metal Converters for Low Emission Vehicles. SAE Transactions, Paper No. 920093, pp. 19-30.

Terres, F., Weltens, H. and Froese, D. 1996. Electrically Heated Catalyst-Design and Operation Requirements. SAE Transactions, Paper No. 961137, pp 293-301

Yaegashi, T., Yoshizaki,K., Nagami, T., Sugiura, S., Yoshinaga, T. and Ohsawa, K. 1994. New Technology for Reducing the Power Consumption of Electrically Heated Catalysts. SAE Transactions, Paper No. 940464, pp. 95-102. 